\title{
Integrating Built Heritage in Development Planning: Small and medium towns of Gurgaon District
}

\author{
Parul G Munjal
}

\begin{abstract}
Rapid growth of cities is a reality addressed in the formulation of Sustainable Development Goals (SDGs) as a part of the United Nations Development Programme (UNDP). Goal 11 proposes 'improving urban planning and management through participatory and inclusive ways' [1]. While this is an obvious ideal, the challenge lies in operationalizing it. In the many layers of a typical urban context in India, one is that of built heritage. One that is marginalized in the process of development planning, particularly in areas such as the Gurgaon District of Haryana that has seen unprecedented urban growth and transformation over the last few decades [2]. The study approaches sustainable development from the lens of built heritage and socio-cultural processes revolving around it in the given context.
\end{abstract}

The research focus is on built heritage of small and medium towns in the Gurgaon District and its linkages with the physical, socio-political and developmental context. The towns of Sohna, Farrukhnagar and Garhi Harsaru in the District have been taken up for study. The three towns are spread across three different Development Plans prepared for Sohna, Farrukhanagar and Gurgaon-Manesar Urban Complex. A critique of the developmental planning approach highlights it's disconnect with built heritage [3]. Mapping of the socio-political context and various on-ground processes of maintaining and managing of built heritage by the local community point towards connections with development that helps sustain the built heritage. There are community linkages, associations and values grounded in the context that play a significant role in the process.

The study reveals that built heritage has an integral relationship with its physical and ecological context, and represents, along with being impacted by, social and political events in the past and present. Hence, historical as well as contemporary positions find a place in the narrative. The community led processes of present day are layered with meanings, understanding which can pave the way for a participatory and inclusive approach towards development, rather than forcing a one size fits all solution.

Keywords: built heritage, community linkages, participatory approach, inclusive approach, sustainable development, planning.

Revised Manuscript Received on March 2, 2020.

* Correspondence Author

Parul G Munjal*, Sushant School of Art and Architecture Ansal University, Gurgaon, Haryana. Email: parul.g.munjal@gmail.com, parulgargmunjal@ansaluniversity.edu.iin

\section{INTRODUCTION}

$\mathrm{T}$ here are diverse processes of urban development planning at play in India, ranging across scales and scenarios. While formal planning tools are generated to govern this in the form of master plans or development plans by town and country panning departments of each state, many decisions on ground are guided by informal political and economic forces. Segments such as heritage are addressed in the master plans of cities like Delhi, as these include a section on conservation of built heritage and conservation strategy, along with provision of heritage zones, archaeological parks and special conservation plans [4]. Development plans prepared for controlled areas identified within Gurgaon District encompassing small and medium towns represent the other end of the spectrum. These are more recent phenomena, with the first development plan for Gurgaon formulated in 1982 and those of Farrukhnagar and Sohna in 2012 and 2008 respectively [5]. Hence, alternative processes have guided development here more than formal ones. The present study maps the processes that establish linkages of heritage with the larger physical, ecological, social and political context in small and medium towns of Gurgaon District. This is intended to help establish a framework for inclusive and participatory development that is responsive to the current processes at play around built heritage, driven by local stakeholders.

The study is positioned in Sohna, Farrukhnagar and Garhi Harsaru that are small and medium towns in the Gurgaon District, with further focus on four sites; Shiv Kund and Shahi Masjid in Sohna, Sitaram-Mandir Gurudwara in Farrukhnagar and Baba Bhorangi Shah Ashram in Garhi Harsaru. The District is of particular interest, as it showed the highest percentage decadal growth rate of urban population from 2001 to 2011 among the 21 districts of Haryana. ${ }^{1}$ The four sites were chosen based on the premise that these are unprotected ${ }^{2}$ sites with collective ownership and in use by the local community, as these present the most active participation of nongovernmental stakeholders in the process of valuing, conserving and using built heritage.

${ }^{1}$ The State average percentage decadal urban growth rate is 44.25 while that of Gurgaon District is 236.53 [2]

Without any legal protection from Department of Archaeology and Museums at the state level or Archaeological Survey of India at the national level 
The study enables an examination of inclusivity and participation in development planning with respect to built heritage and the context in which it is situated. The first step towards this is outlining global and national approaches that integrate heritage and development planning.

\section{BUILT HERITAGE, DEVELOPMENT, INCLUSIVITY AND PARTICIPATION}

Over the last decade, the relationship of development with culture has been acknowledged and discussed in international conventions and guidelines [6]. The New Urban Agenda set out as a part of the 'Conference on Housing and Sustainable Urban Development' focuses on sustainability, people and cities [7]. This is meant as a universal standard setting document that addresses tangible and intangible cultural heritage as a resource that can be leveraged for development. Clause 124 places culture as a priority component in urban planning instruments that include master plans, codes, guidelines, policies and strategies [7].

The current scenario on ground is quite different, particularly in case of small and medium towns in India. The towns with population below 100,000 have limited access to civic services [8] and have poor capacities at the urban local body level. National schemes such as Jawaharlal Nehru National Urban Renewal Mission and Heritage City Development and Augmentation Yojana (HRIDAY) and Pilgrimage Rejuvenation and Spirituality Augmentation Drive (PRASAD) that have initiated addressing heritage as a cross cutting theme or area of focus, respectively, also skip these towns.

The Recommendation on Historic Urban Landscape (HUL) laid out by United Nations Educational, Scientific and Cultural Organization (UNESCO) in 2011 considers urban heritage as 'a social, cultural and economic asset' and recognizes 'the importance of the social, cultural and economic processes in the conservation of urban values' [9]. This positions urban heritage in its context holistically, while acknowledging layers and processes from the past as well as present, which in turn makes it inclusive. The HUL approach lists urbanization and globalization, development and environment as threats to urban settlements and their historic areas. To mitigate, it recommends development of policies and tools; capacity building, research, information and communication, in an inclusive and participatory manner [9].

Inclusivity and participation have been a significant part of the global discourse on heritage as well as development over the last few decades. In response to criticism of the exclusivity of the authorized heritage discourse [10], five Cs were included in the objectives of the World Heritage Convention, namely Credibility, Conservation, Capacity-building, Communication and Communities in 2002 and 2007 [11]. Goal 11 of SDGs outlined by UNDP emphasizes on 'improving urban planning and management through participatory and inclusive ways' [1]. Public participation is now being positioned as an integral part of urban conservation as well as development that links with the 'politics of identity' [12] and 'power dynamics' of the community [3].

While public participation is focused towards inclusion of all stakeholders, inclusivity as a whole is more encompassing and can be viewed from the perspective of not only including multiple perspectives and paradigms from various parts of the world, but also addressing history, politics, heritage, traditional knowledge etc. The need for a regionally contextualized approach has been identified in the field of heritage conservation [13] as well as urban development [14]. The current study with focus on heritage and development in small and medium towns in Gurgaon District is meant to identify critical aspects that can inform the way forward in the given context.

\section{GURGAON DISTRICT AND THE TOWNS}

The District came into existence under the British in $19^{\text {th }}$ century and after many iterations, took its present definition in 2004, as a much reduced version of its previous extent. The District is further divided into five administrative subdivisions or Tehsils, namely Pataudi, Gurgaon, Farrukhnagar, Manesar and Sohna. The percentage urban decadal growth from 2001 to 2011 is highest in Gurgaon Tehsil, followed by Sohna and Farrukhnagar.

Table- I: Percentage decadal variation in population from 2001 to 2011 across Tehsils of Gurgaon District [2]

\begin{tabular}{|l|l|l|l|l|}
\hline $\begin{array}{l}\text { S. } \\
\text { No. }\end{array}$ & Tehsil & Total & Rural & Urban \\
\hline 1 & Pataudi & 18.87 & 16.07 & 24.6 \\
\hline 2 & Gurgaon & 112.94 & -69.33 & 280.05 \\
\hline 3 & Farrukhnagar & 23.3 & 21.52 & 41.93 \\
\hline 4 & Manesar & 43.87 & 14.94 & NA \\
\hline 5 & Sohna & 33.18 & 15.37 & 95.73 \\
\hline \multicolumn{2}{|l}{ District Total: } & 73.14 & -16.43 & 236.53 \\
\hline
\end{tabular}

Table- II: Class, population and status of towns in Gurgaon District [2]

\begin{tabular}{|l|l|l|l|l|l|}
\hline $\begin{array}{l}\text { S. } \\
\text { No. }\end{array}$ & $\begin{array}{l}\text { Name of } \\
\text { Urban Area }\end{array}$ & Class & $\begin{array}{l}\text { Statutory/ } \\
\text { Census } \\
\text { Town }\end{array}$ & Population & $\begin{array}{l}\text { District/ } \\
\text { Tehsil } \\
\text { HQ }\end{array}$ \\
\hline 1 & Gurgaon & I & Statutory & $8,86,519$ & $\begin{array}{l}\text { District \& } \\
\text { Tehsil } \\
\text { HQ }\end{array}$ \\
\hline 2 & Manesar & III & Census & 23,448 & $\begin{array}{l}\text { Tehsil } \\
\text { HQ }\end{array}$ \\
\hline 3 & Sohna & III & Statutory & 36,552 & $\begin{array}{l}\text { Tehsil } \\
\text { HQ }\end{array}$ \\
\hline 4 & Pataudi & III & Statutory & 20,418 & $\begin{array}{l}\text { Tehsil } \\
\text { HQ }\end{array}$ \\
\hline 5 & Hailey Mandi & III & Statutory & 20,906 & \\
\hline 6 & Farrukhnagar & IV & Statutory & 13,513 & $\begin{array}{l}\text { Tehsil } \\
\text { HQ }\end{array}$ \\
\hline 7 & Badshahpur & IV & Census & 15,593 & \\
\hline 8 & Bhondsi & IV & Census & 17,410 & \\
\hline 9 & $\begin{array}{l}\text { Garhi } \\
\text { Harsaru }\end{array}$ & V & Census & 7,894 & \\
\hline & & & & & \\
\hline
\end{tabular}


The impact of the high urban decadal growth is evident in expansion of existing urban areas and transition of villages to towns, in terms of population size and occupation. The urban growth has been extremely high in Gurgaon city, changing it from a small town to a big city with a population of $8,86,519$ [2]. The decade from 2001 to 2011 witnessed an increase in urban areas, with Bhondsi, Badshahpur, Garhi Harsaru and Manesar designated as census towns, implying that they do not have an urban local governance system. ${ }^{3}$ Census of India, 2011 lists eight small and medium towns ${ }^{4}$ in Gurgaon District, including the four census towns. The population range in the towns is from 7,894 to 36,552 with Garhi Harsaru at the minimum end and Sohna at the maximum end [2]. Each of the categories of towns from Class II to VI, demonstrate different dynamics in terms of infrastructure, services and capacity, requiring specific approaches [8]. Considering that the study focuses on small and medium towns, there is an opportunity to study built heritage across class III, IV and V in the District of Gurgaon, represented by Sohna, Farrukhnagar and Garhi Harsaru respectively.

The city of Gurgaon that has shown unprecedented expansion in terms of population size was smaller than Farrukhnagar and Sohna as per the Census of 1881. From 1901 to 1941 , Gurgaon and Sohna continued to be urban centers. The census data suggests that Pataudi and Farrukhnagar were categorized as urban intermittently during this time-period. After India gained its Independence in 1947, Hailey Mandi was an added to the list of towns and the population of Sohna, Farrukhnagar and Pataudi was reduced due to the Partition. The Muslim population that was a dominant segment in these towns moved out, but the number of Hindus who moved in were not as many.

The percentage decadal growth rate of Bhondsi, Manesar and Garhi Harsaru is over 50 in the decade from 2001 to 2011. Sohna and Farrukhnagar also have a higher percentage decadal growth that the national urban percentage decadal growth rate of 31.8. Hence, these five towns are the ones that have shown rapid urban growth from 2001 to 2011.

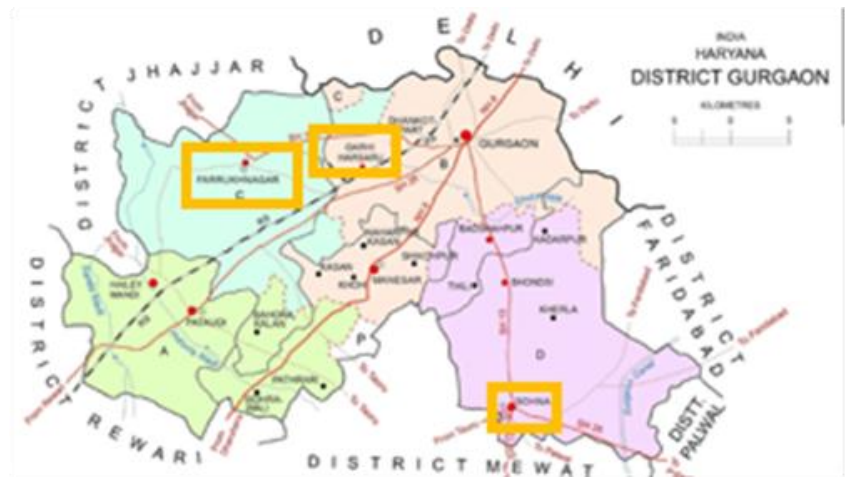

Fig. 1. Gurgaon District with all towns marked in red [2], highlighting the three small and medium towns taken for study in yellow boxes

\footnotetext{
${ }^{3}$ Badshahpur, one of the Census Towns as per 2011 Census was included in the region under Municipal Corporation of Gurgaon by 2015.This demonstrates the rapid growth of Gurgaon city, expanding to include more towns and villages.

${ }^{4}$ With population above 5,000 and less than 100,000 .
}

The entire District is divided into five areas, namely Gurgaon, Gual Pahari, Sohna, Farrukhnagar and Pataudi-Haily Mandi for which development plans were prepared by the Town and Country Planning Department of Haryana. The development plans extend beyond the municipal boundaries and focus on land use planning for 2031. The development plans briefly mention the heritage of the towns and state that heritage shall be protected, but due to lack of mapping of heritage on the development plans and focus on areas outside the core settlements, it is addressed tokenistically at best. A case in point is the Badshahpur Bawdi over which a sector road was proposed in the Development Plan [15] and its filling up for construction work was stopped in January 2018 through intervention of Sushant School of Art and Architecture, Ansal University. ${ }^{5}$

Based on their basic infrastructure index, the small and medium towns of India have been categorized ${ }^{6}$ as achievers, aspirers, average, laggards and deprived [8]. Sohna is in the average category, while Farrukhnagar and Garhi Harsaru are laggard. As per the study by NIUA [8], the average category towns can build their capacity along with central funding support, while laggard towns need to be supported through central and state funding.

Table- III: Percentage growth rate of population and category in terms of basic infrastructure

\begin{tabular}{|l|c|l|}
\hline Name of town & $\begin{array}{l}\text { Growth Rate Town } \\
\text { (Census 2011) }\end{array}$ & $\begin{array}{l}\text { Category (basic } \\
\text { infrastructure) }\end{array}$ \\
\hline $\begin{array}{l}\text { Garhi Harsaru (46) } \\
\text { (Census Town) }\end{array}$ & 50.94 & Laggard \\
\hline Farrukhnagar (MC) & 41.93 & Laggard \\
\hline Sohna (MC) & 32.58 & Average \\
\hline
\end{tabular}

Hence, while all three towns taken up for study demonstrate a decadal growth rate that is higher than India's average, they are laggard or average at best in terms of access to basic infrastructure. This is the case, when the focus of local governance is currently on provision of basic infrastructure. The capacity to address built heritage as a concern is far from reality in such a context. This implies that the local governance in the towns is not in a position to focus on built heritage.

\section{HERITAGE RESOURCES AND CONTEXT}

\section{A.Shiv Kund and Shahi Masjid, Sohna}

Among the three towns, Sohna has the maximum number of historical layers, starting from fourteenth century. Farrukhnagar dates from eighteenth century and Garhi

\footnotetext{
${ }^{5}$ Students and faculty visited the site on Jan. 18, 2018. We found that the Bawdi was being filled with earth and spread the word, resulting in the filling being stopped from that point onwards.

${ }^{6}$ Based on an index of basic infrastructure, dependent on the percentage of households with (i) access to tap water from treated source within premises; (ii) flush latrine facility with piped sewer within the premises; (iii) bathroom within the premises; and (iv) waste water outlet connected to closed drainage (HSMI-HUDCO Chair-NIUA 2016, p. 111) 
Harsaru has associations from fourteenth century though existing built form is from eighteenth century and onwards. Traditional livelihoods continue in the form of silver jewelry making, shoe making and production of food items.

At present, the town of Sohna is a Municipal Council ${ }^{7}$ with 21 wards, each governed by an elected representative. As per the 2011 Census of India, the town has a majority of Hindu population with $88.54 \%$ Hindus and $9.85 \%$ Muslims [2]. The urban settlement abuts the Aravallis to its southwest and

Sohna shows diversity in built heritage resources, with a hot Sulphur spring known as Shiv Kund that has historic structures over and around it and is a social, religious and medicinal hub for local residents and visitors. There are many mosques dating from fifteenth to eighteenth century, tombs, fortifications, residential mansions, and institutional buildings from the nineteenth century and onwards in Sohna. One of the prominent mosques is Shahi Masjid that is documented as being built in 1301, though the built form seems to date from the fifteenth to sixteenth century. ${ }^{8}$ Both Shiv Kund and Shahi Masjid are unprotected historic structures that are maintained and managed by local stakeholders without any direct support from the government. These are undergoing continuous changes in the built form, with multiple processes of decision making at

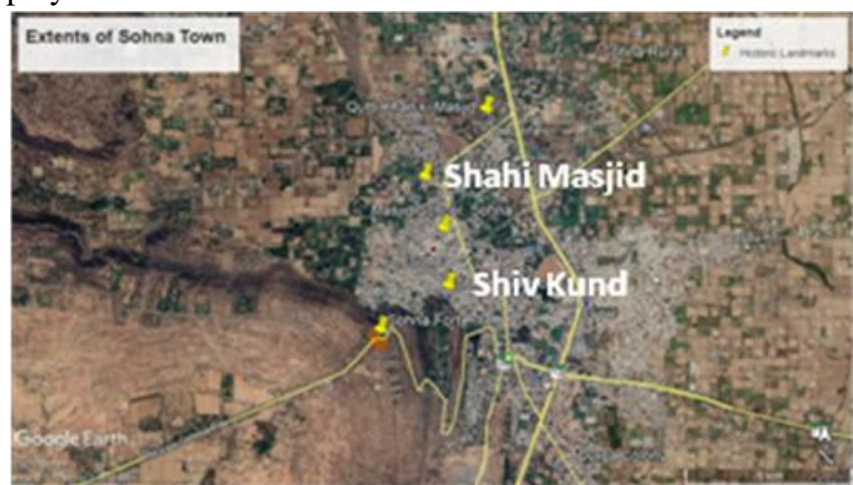

Fig. 2. Satellite imagery of Sohna town and its setting, November 2019

Shiv Kund is located at the heart of the core town that has been dominated by Hindu population since Independence. It is located in Ward 16 that includes Thakurwada, Pathanwada, Gujjar Ghati and Library Chowk area. Thakurwada houses Rajputs while Pathanwada originally had Muslims who migrated to Pakistan after the Partition of India and were replaced by Punjabis. ${ }^{9}$ The Library Chowk area is predominated by the baniyas or merchant class. The area surrounding the Kund is referred to as Mahajan Mohalla, and the commercial activity on streets towards the north of the Kund is supported by the bania or mahajan community. The residences to the south of the Kund are still occupied by descendants of the original residents. These courtyard houses with stone walls and traditional

\footnotetext{
${ }^{7}$ Municipal Committee until 2014 with 15 wards.

${ }^{8}$ Based on comparative architectural study of the region.

${ }^{9}$ Based on interview with Rajesh Raghav and Sanjay Vashishth
} play.

architectural vocabulary could be dating from eighteenth century and suffer due to subdivisions and lack of maintenance.

There have been concerns about reducing levels of water in the spring, for which illegal mining in the larger region around, and the use of ground water from the area around the Kund for water supply have been identified as possible reasons.

The price of land in the core town area is one fifth of the price in the new colonies being established ${ }^{10}$. This may be a deterrent for the local population to move out into the new colonies. At the same time, there is a possibility that the economically stronger categories of residents would move out to the newer areas, especially if they do not find value in living in the core town. The presence of the Kund, benefits drawn from the social, economic and political environment and the ties that they have with the place have kept some of the older families in the core town until now ${ }^{11}$, while many have moved out to Delhi and other cities due to better livelihood possibilities and aspirations.

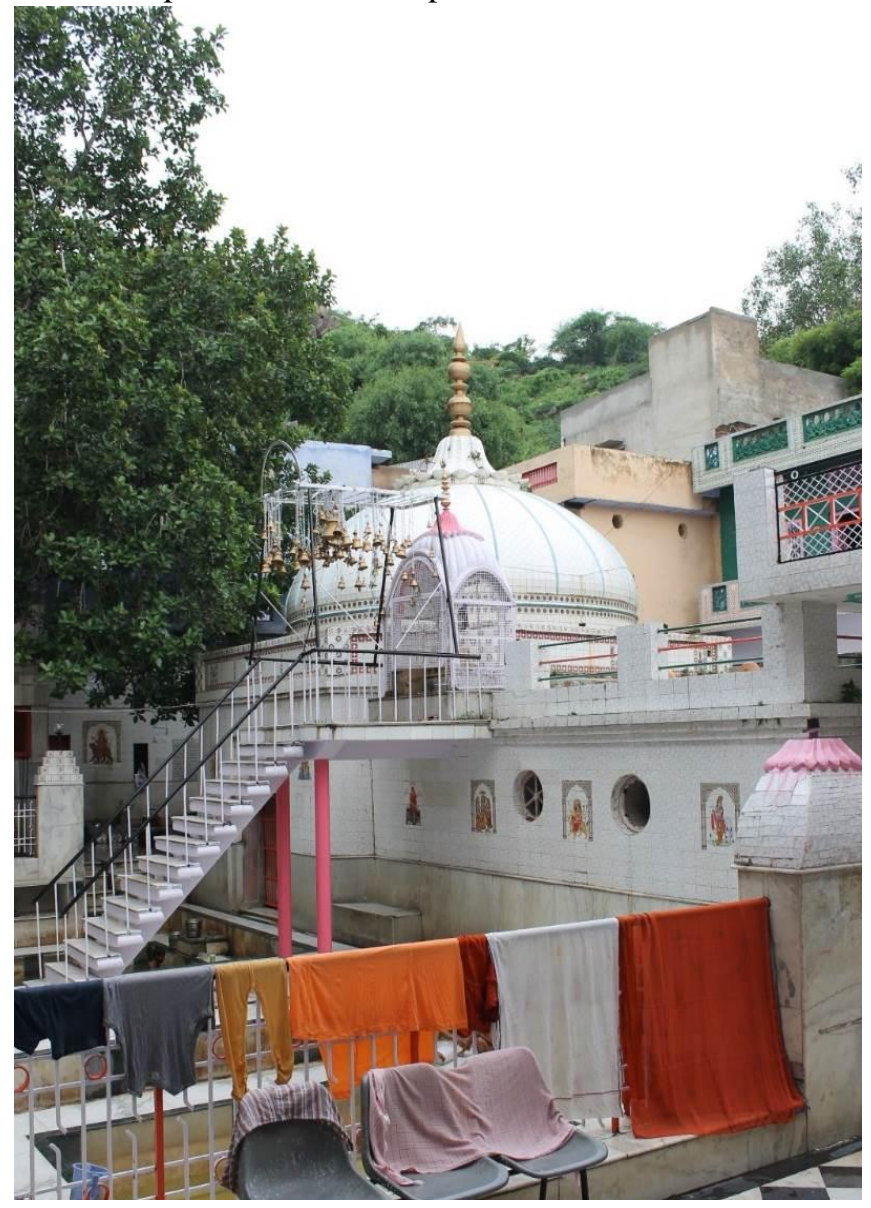

Fig. 3. The dome covering the Sulphur spring is surrounded by structures on all sides, added by patrons from the 16th century and onwards (Author, 8 August 2015)

\footnotetext{
${ }^{10}$ Based on interview with Santosh Taneja

${ }^{1}$ Based on interview with residents such as Sundar Pal who have ancestral roots in the place as well as later migrants such as Harish Nanda
} 
As per the Sohna Final Development Plan (FDP) - 2031 $\mathrm{AD}$, the projected population of the town, including urban villages is $6,40,000$, that is about ten times the population in $2011^{12}$ [16]. The density of population in the town was 137 Persons Per Hectare (PPH) in 2011. The population in the Town is anticipated to reduce due to spill over into the induced urban development around. Hence, the proposed density for Sohna town is $90 \mathrm{PPH}$ and $300 \mathrm{PPH}$ in new residential areas as per the FDP [18]. This thinning of population may affect the current relationship of the people living around with the Kund. The Kund is marked on the FDP and mentioned in the introduction to the town, but no ecological concerns with respect to maintaining its significance have been listed in the proposals for development.

The Shahi Masjid complex is on the northern edge of the town, with less sparse and more recent development around, though the area to the north and west of the site is populated with remains of settlement under Kambohs and Khanzadas in the fifteenth to sixteenth century period. As majority of the Muslim population from the town had migrated out at the time of Partition, the current Muslim population in Sohna has settled in over recent decades. The complex was abandoned for a while before the family of the current Maulana re-established it as a mosque in the 1960s.

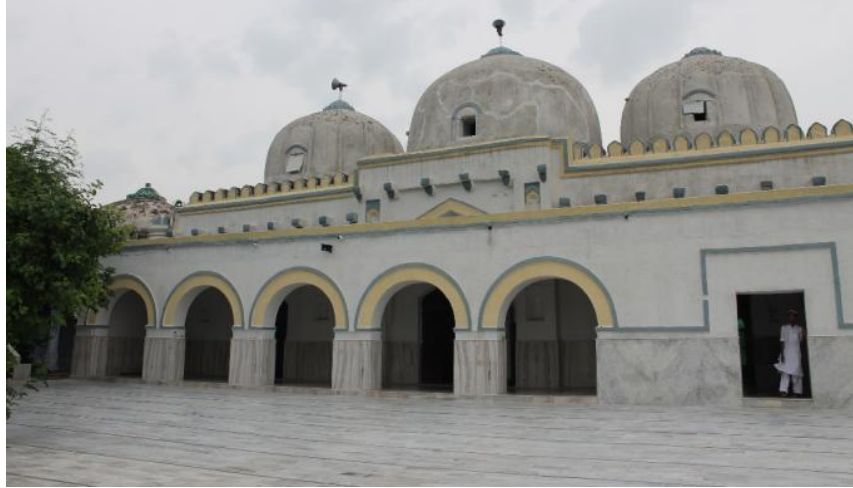

Fig. 4. Shahi Masjid with additions made in the form of added colonnade, marble cladding and paint work (Author, 8 August 2015)

As per information from the residents and a Ward Councilor, the Muslim population is sparsely spread across the area near Gurudwara, that lies to the south of the Shahi Masjid, Pir Colony ${ }^{13}$ and Band Colony near the Masjid; and around ITI Colony, near the Bypass, at the southern periphery of the town. A water channel or nallah was said to flow to the north west of the Masjid that has now been converted to Rajiv Gandhi Park. This is the only park in the town of Sohna, used by morning and evening walkers and as a recreational green space. Band Colony lies to the north of the park while the area to the south of the park is agricultural

\footnotetext{
${ }^{12}$ Population in 2011 including urban villages was 67785, out of which population of urban villages is 31348 (TCPD 2012b).

${ }^{13}$ Settled about 30 years ago over an earlier kabristan or graveyard.
}

land. The Pir Colony to the west houses the grave of a $\mathrm{Pir}^{14}$ and the residents refer to Sohna as having 105 Pirs. ${ }^{15}$ Visitors who come to offer prayers, particularly on Fridays and for celebrations such as Eid, include the Muslim residents, those who are in the town for work and residents of 20 villages around the Sohna. Hence, the connections of the Masjid have been forged at the local as well as the regional level. The availability of open space around the Masjid complex allows for congregations and its location enables easy access from within the town and the larger region.

The high plinth of the Shahi Masjid could have been resultant of its being built on a natural rocky outcrop situated in a low-lying area. Cunningham [17, p. 136] introduced the mosque as being located on a high mound just outside the town, to the north, in 1882-83. The town of Sohna is situated towards the east of a stretch of Aravalli hills, creating a catchment area that is distinct from that of the area to the west of the hills. Natural feed into an area that coincides with the area that lies to the northwest of the Masjid, enclosed by a bundh or dam. The name of Band Colony is based on the presence of the dam.

In the Sohna Final Development Plan (FDP) - 2013 AD [16], the area is marked as water body/lake with the bundh next to it. Maulana of the Masjid mentioned that the area used to be inundated during rains earlier, remaining dry due to low rainfall over the last few decades. In addition, the stretch of land to the east of the dam and north of the Masjid had turned into a garbage dump, revitalized by the development of Rajiv Gandhi Park over it. The Maulana stated having a role in the process, as he had recommended the cleaning up of the area and development of the park.

With the Aravalli hills winding around the area, the Shahi Masjid and the graveyard ${ }^{16}$ to its southwest, form the edge of the town at present. In the fourteenth or fifteenth century when the Masjid is said to have been constructed, the area around it would possibly have been submerged under water, especially during rains. A rocky outcrop, next to a water body would have been an ideal location chosen by the wali or caretaker to live on, and eventually the construction of the Mosque after his interaction with Ala-ud-din Khilji, as per the story told by the Maulana.

Shahi Masjid hasn't been marked in the FDP proposal for 2031 AD [16] though it acknowledges the presence of the water body, the dam and Aravalli hills, and demarcates a water recharge area to the northwest, and forestland and natural conservation zone to the west and southwest. The area to the east is mapped as part of the development of

\footnotetext{
${ }^{14}$ A Sufi master or spiritual guide

15 Najmul-Hak is documented as a significant holy saint, in whose name a mosque and tomb complex was built in the late $15^{\text {th }}$ or early $16^{\text {th }}$ century, used as a government primary school at present, hence referred to as the Masjid School locally. Alexander Cunningham visited the structure in 1882-83 and documented its architecture along with finding a Farman from Akbar dated 1603-04 AD, attaching resources to sustain the mosque and tomb complex.

${ }^{16}$ Present day Pir Colony situated on a raised mound.
} 
Sohna Town. Hence, the setting of the mosque complex is proposed to remain intact, in the form of the Aravalli hills with the Sohna Fort atop and possibly a revitalized waterbody in future. Beyond this aspect, the connections of the Masjid complex with the pre Rajput layers of the town need to be understood better and the regional significance that has developed over the last few decades needs to be acknowledged in development planning.

\section{B.Sitaram Mandir-Gurudwara, Farrukhnagar}

Farrukhnagar is a fortified town with one state protected palace and one nationally protected stepwell. It has fortification walls, bastions, gates, bazaar streets, mansions, mosques and a painted memorial domed pavilion as unprotected historic structures. In 1910, the town was described as organized around two main bazaar streets running perpendicular to each other [18]. The two main streets are still legible in the structure of the town. The Jami Masjid or main congregational mosque of the town was built in $1733 \mathrm{AD}$ by the Biloch Faujdar Dalel Khan who founded the town was located on the main node of the town formed at the intersection of the two bazaar roads [18].

The built form defining the bazaar street is typically single or double storied, meant for purely commercial use with ornamental facades incorporating colonial features along with the regional brackets and overhangs. The bazaar itself has shifted out towards Delhi Gate and the main bazaar streets are lying vacant and in a poor state of repair.

Today, Farrukhnagar is a Municipal Committee spread over an area of 20.24 square kilometers, with a population of 13,513 as per 2011 Census, hence designated as a small town ${ }^{17}$. Domination of the Hindu community over Muslims is apparent, with $98.32 \%$ Hindu population. The town has $30.69 \%$ scheduled caste population and $30.48 \%$ working population [2]. It has a high slum population of $23.03 \%$, highest among all urban areas of the district (ibid.). Jains, Pandits, Baniyas, Karigars and Punjabis are distributed within the city in clusters. The original local population was reduced and displaced as result of the abandonment of the town in twentieth century due to the decline of salt trade and due to the Partition of India

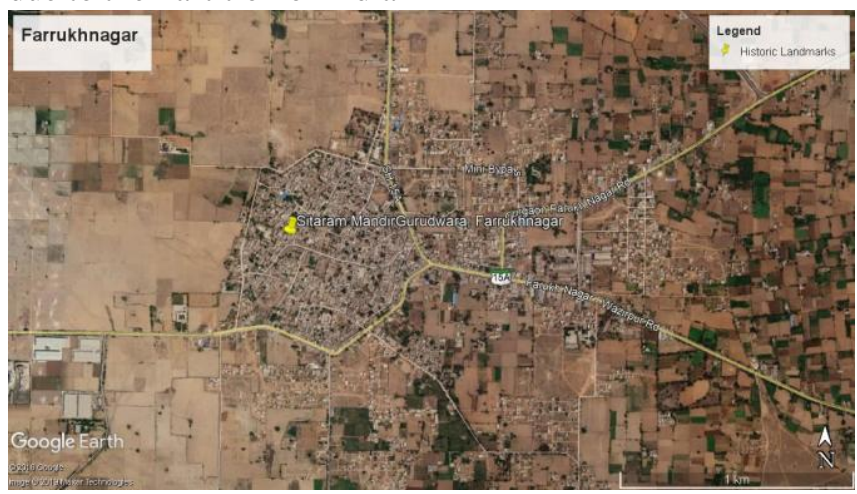

Fig. 4. Satellite image of Farrukhnagar town and its setting. The fortified town retains the octagonal profile as well as some gates and bastions defining it (November 2019)

\footnotetext{
${ }^{17}$ Class IV category that ranges from 10,000-20,000
}

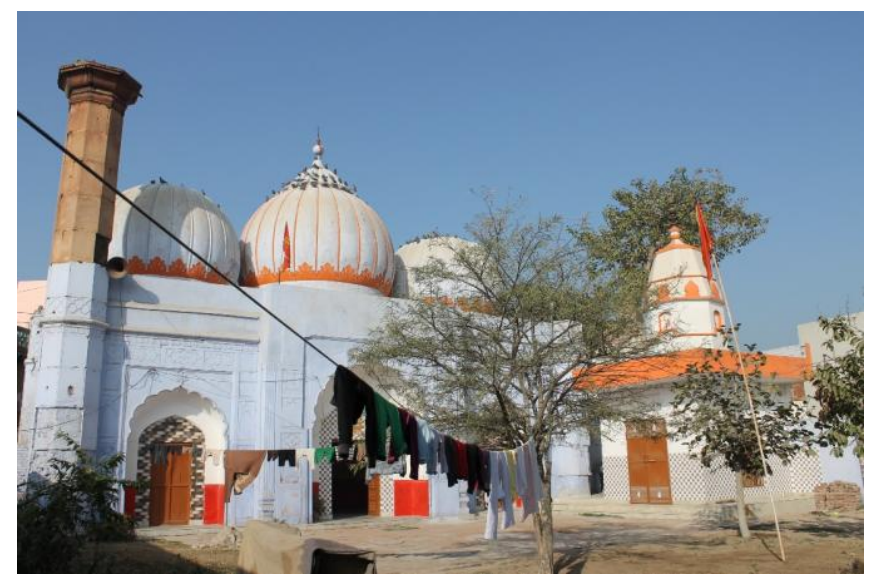

Fig. 5. Main prayer hall of the Sitaram Mandir Gurdwara painted and new temple added in the courtyard. The clothesline in the foreground indicates its residential use by the priest and his family (Author, 27 December 2016)

The town serves as the headquarters of Tehsil Farrukhnagar that includes 51 villages around the town. Located about 20 kilometers from Gurgaon, parts of the agricultural land around the town has been converted for urban use in the form of development of large educational campuses and commercial complexes over the last two decades. There has been a strong shift of livelihood patterns of the local community as the original agricultural land around the core town and surrounding villages has been bought by private developers for urban projects. The three most important commodities manufactured in Farrukhnagar are shoes, moorhas or backless seats made out of local grass, and iron trunks [2]. The moorha making craft was based on the plentiful growth of 'munj' grass in the area [18]. The local ecosystem that supported the craft is facing challenges due to recent urban development, hence posing a threat to the craft.

The influx of migrants from Punjab after the Independence resulted in a dominant Hindu population and the conversion of the Jami Masjid to Sitaram Mandir Gurudwara by the migrants who did not have a temple of their own and saw the abandoned mosque as an opportunity of reuse. While it speaks of marginalisation of a particular earlier use and religious adherence, there is a projected celebration of secular ideals by placing the Guru Granth Sahib along with idols of Sita-Ram in the three chambers of the mosque. The property is under the ownership of the Haryana Waqf Board ${ }^{18}$ but is used and managed by the Punjabi families who migrated to Farrukhnagar following the Partition.

The Punjabi community manages the property by collecting a Chulha Tax. It has attracted donations for activities such as replacement of the eighteenth century

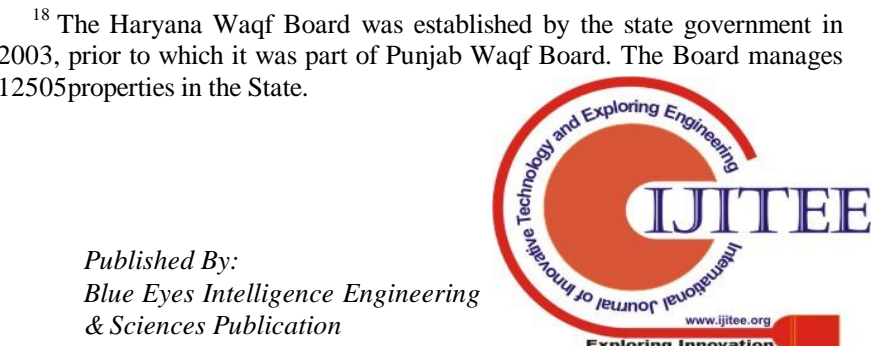


gateway with a brick and concrete structure, painting the stone surfaces in saffron and white and construction of a temple structure within the courtyard, over the recent years. There is an implicit motivation of bringing down the one remaining minaret of the structure, to fully appropriate it as a Hindu temple and Gurdwara, though the Waqf ownership and realization of potential threat to human life and the structure during the demolition attempt has kept this under check. There is no involvement of the urban local body in any decision-making or maintenance of the site.

The Draft Development Plan (DDP) prepared for the town by the Town and Country Planning Department of Haryana Government [19], gives a brief introduction of the town including historic significance. Jami Masjid, Shish Mahal, Baoli and Delhi Darwaza are indicated on the DDP of Farrukhnagar but the induced growth projected over the next decades does not address any factors relating to the heritage resources of the town. Interestingly, there is no mention of the Jama Masjid being used as the Sitaram Mandir Gurudwara in the DDP. The social, economic and cultural processes on ground lack nay representation in development planning.

The DDP, 2031 proposes a world trade hub, a leisure hub and an entertainment hub around Farrukhnagar for inducing growth of the town to reach a projected population of 125,000 by 2031. According to the DDP of Farrukhnagar, the vicinity of Sultanpur National Park that is a designated Eco Sensitive Zone, is also another factor for the growth of population' [19, p. 2]. This comes across as a contradiction in itself as the presence of an Eco Sensitive Zone necessitates a cautious approach towards development in order to ensure that there is no negative impact on the Sensitive Zone. Hence there is a poor level of sensitivity towards natural as well and built heritage and understanding of processes revolving around these in the formal mechanisms of development planning.

\section{C.Bhorangi Shah Ashram, Garhi Harsaru}

Garhi Harsaru is a small town that is best known as a railway station on the line connecting Delhi and Rajasthan. Although designated as a Census town in 2005, as it has a population of 7,894 and over $79.7 \%$ of total working population is employed outside the agriculture sector ${ }^{19}$ [2], it is governed by a village panchayat. The town has $23.49 \%$ Scheduled Caste population and the total working population is $29.96 \%$ of the total population ${ }^{20}$ [2].

Most of the agricultural land in the immediate vicinity has been sold off to developers, leaving only some locally owned cultivated fields. Sector 88 and 89 of Gurugram ${ }^{21}$ lie about 200 meters to the south of the settlement, as does the municipal boundary of Gurugram [15]. High-rise housing projects are being built by 'mega' private builders ${ }^{22}$ about two kilometers to the south of the town. With the municipal boundary of Gurugram and the railway line located less than 200 meters to the south of Garhi Harsaru, the land has high potential for urban development, with the expansion of Gurugram.

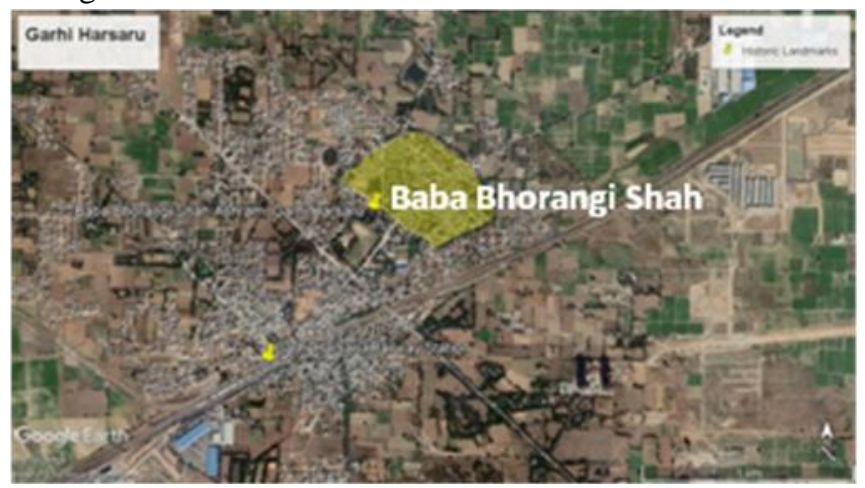

Fig. 6. Satellite image of Garhi Harsaru with the core settlement highlighted in yellow and Bhorangi Shah Ashram located just at the edge of the settlement (November 2019)

Although the physical remains of the mansions in the town and the mosque that is part of the area under study suggest late Mughal vocabulary of the eighteenth century, it is difficult to assign a date of origin to Garhi Harsaru. There is a legend about rich Jain merchants of the town who owned the mansions and got the fortress in dowry from a Seth of Rewari. The village was subdivided on the basis of social and religious divisions. Bhangis, Chamars, Brahmins, Kumhars, Malis, all lived in specific designated areas and the Jain merchants occupied the center of the village. One of the mansions of Jains still stands and is still being used as a residence of two family members ${ }^{23}$.

The Bhorangi Shah Ashram is an active landmark in the town, with local residents, those from surrounding villages and people with roots in Garhi Harsaru but now live elsewhere, flocking to offer prayers on Thursdays. The complex is known for the spiritual powers of Sayyed Baba or Baba Bhorangi Shah who resided here and is buried here. The complex includes his shrine, a late Mughal mosque that is now known and valued as being the abode of a saint for over five decades till he left his body in 2017 and a village shrine referred to as Dada Bhaiyya. The complex is also under Waqf Board ownership but managed by the local residents. Over the last couple of decades, people from surroundings areas have settled here and built houses outside the core settlement. This has changed the demography of the town and brought in newer dimensions of use and value for the site. The village panchayat does not play any role in the maintenance or management of the site, while local political leaders do use the site as a platform for visibility. Physical interventions in terms of repairs, white washing and addition of new structures are undertaken by the local residents in a

\footnotetext{
${ }^{23}$ Based on interview with Roop Chand Sharma
} outside the agriculture sector.

\footnotetext{
${ }^{20}$ Below the District average of $34.78 \%$.

${ }^{21}$ Gurugram is the official name of Gurgaon since September 2016.

${ }^{22}$ DLF, Rahejas, SS Group, among others.
} 
partially planned and more adhoc manner, as they claim that it is the Baba's will that motivates any contributions and interventions on site.

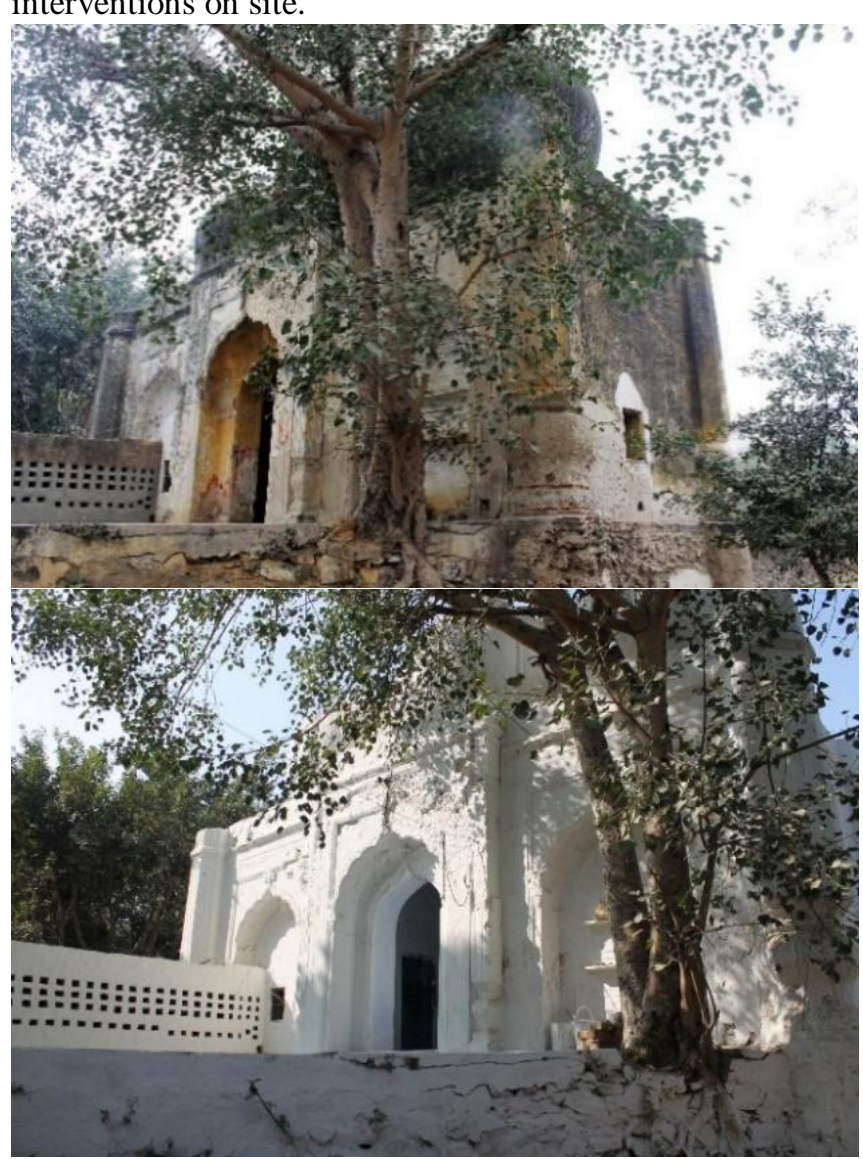

Fig. 7 a-b. The mosque as visible from the northeast corner in February 2016 (top) with patchy paint and in December 2016 (bottom) with a fresh coat of whitewash (Author, 28 February 2017; 27 December 2017)

The location of the site next to a government boys school that has a large playground has created connections with the Ashram, as an annual sports event is organised in the ground during which food is prepared and distributed at the Ashram at a large scale. Being outside the core settlement, there are new pedestrian thoroughfares created from within the site and children from schools around the settlement come to the site for lunch on every Thursday, when the local stakeholders cook and distribute food. Such processes have generated social cohesion and associations with the place, beyond the scared values that it continues to have.

Clause number 12 of the FDP mentions that 'monuments, heritage sites, special areas of aesthetic, sentimental or historic value which require protection shall be protected' [15]. But, no structures have been listed or demarcated on the spatial plan and no impact assessments have been carried out with respect to the heritage sites in the preparation process of the FDP.

The Ministry of Environment and Forests (MoEF) declared Sultanpur National Park as an Eco Sensitive Zone (ESZ) on January 27, 2010 and area in the five-kilometer radius around the National Park was included in the Zone. The village Garhi Harsaru was also listed as a part of the ESZ in the notification [20]. The FDP 2031 incorporated this notification by MoEF and the demarcation of the radius of five kilometer on the spatial plan shows a part of the village within the ESZ. The entire region to the northwest of the settlement is proposed as agricultural land and a pocket of 45 hectares between the settlement and the railway line has been reserved for idle parking along the railway line adjoining the village Garhi Harsaru ${ }^{24}$, categorized under the landuse of Transport and Communication. In order to cater to the future growth of the area, Transport Nagar and Container Depots have been proposed adjoining to Garhi Harsaru Railway Station on Delhi-Rewari Railway line [15].

According to the FDP 2031, the restrictions applicable to the ESZ as per the MoEF notification have to be followed and implemented [15]. The MoEF Notification asked the State Government to prepare a Zonal Master Plan for the ESZ, within one year of the date of publication of the notification [20]. The Notification lists 12 points to be considered for preparation of the Zonal Master Plan. These include a clause that no land under 'green uses' will be converted to 'non-green uses' except for accommodating the residential needs of the existing population and its natural growth; improvement of roads and bridges infrastructure and construction of public utility or community building, without the approval of the State Government. The Zonal Master Plan has not been prepared and approved till date.

Hence, while larger environmental concerns that are identified by the central government find representation in development planning, those relating to built heritage are absent and there is no involvement of central, state or local bodies in this respect.

\section{CRITICAL ASPECTS OF PHYSICAL SETTING}

The four cases represent diversity in terms of their setting, representing various types of interdependence on their physical environment. The Shiv Kund came into existence due to the emergence of the natural hot sulphur spring, at least five centuries ago. The study of the geology of the region establishes that a relationship of the spring with the alluvium covered area to the west and the quartzite of the hill. Hence, the current issue of reduced water flow is clearly linked with the geographical setting, expanding the discussion to beyond the site. The spring was located outside the town originally, as substantiated by the mention in Ain-I-Akbari and popular history. At present, the urban development extends to the west of the site as well. The impact of human activity on the land in the form of changed patterns in ground water recharge, extraction of ground water and mining of rock needs to be studied further to find the cause of the reduced water in the spring. As the significance of the site is primarily due to the presence of the hot sulphur spring, the continuity of the significance is dependent on geological and developmental considerations

\footnotetext{
${ }^{24}$ Opposite to wholesale market proposed in sector 99A
} 
around the site. The Development Plan of Sohna demarcates the area to the west of the site as a combination of forestland and natural conservation zone and some area to the north as ground water recharge zone. While the present Development Plan addresses environmental concerns, it does not address this linkage of the spring with the concerns. It is important to implement these proposals, placing the hot spring as a focal point.

Over the last few centuries, the center of the town shifted from areas further north and west to that around the Shiv Kund. The current developmental agenda focuses on an expanded municipal boundary with the area to be developed until 2030 being 14 times the current area under the town and villages. The new residential and commercial areas are to be established to the north, south and east of the present town. This has the potential of marginalizing the old town, with the focus of urban local bodies shifting to the newer areas causing worsened living conditions and out migration of the families that have been associated with the Shiv Kund over generations. The visitorship at the Shiv Kund is impacted due to the presence of Prem Bhagat Ji, a healer in the town and the linkage with Milakpur Mela organized around Holi due to which footfall increases at Sohna. These linkages can be strengthened further in future planning.

The Shahi Masjid is located to the north of the current urban settlement, next to a dam that contained water next to the complex. If we reimagine the landscape of the area when the mosque was built, based on nineteenth century documentation and the popular story associated with its foundation, the setting comes across as picturesque, with the Aravallis in the backdrop, a stream flowing next to it, feeding a water body located adjacent to the site. The presence of a rocky outcrop would have been the reason for the construction of the mosque here. At present, the stream has been converted to a recreational green space for the city dwellers and the water body confined by a dam is now an ornamental pool as a part of the green space. The complex is conveniently accessible for city dwellers as well as followers from surrounding villages, being located at the northern end of the town, without any traffic congestion and with ample parking available next to the recreational green space. The significance of the mosque complex lies in its being the largest active mosque of the town, that is suitable for large-scale congregations at Eid and smaller ones every Friday. The potential of reimagining the historical physical setting, and ease of accessibility, away from the Hindu dominated dense areas of the town are significant contributions of the physical location that may be considered during future development. Linkages with the over 20 villages from where Muslim population visits the mosque are another significant aspect that needs to be addressed.

The Sitaram Mandir Gurudwara is located at the center of the town, as the Jama Masjid was meant to be when the octagonal fortified town was established in the eighteenth century. Its physical setting at the junction of the two main commercial streets of the town has not changed, but the main commercial activity has moved out. This is a result of development of commercial areas outside the fortified area, due to better accessibility. Punjabi families live in a cluster close to the structure, enabling them to maintain the place. The proposal of the Development Plan focus on economic development through activities that are completely extrinsic to the place and have nothing to do with the identity of the place. The town is in a state of blight, as the demographics continue to change and traditional livelihoods have been disrupted.

In the case of Baba Bhorangi Shah Ashram, the location is at the edge of the original village settlement, now surrounded on all sides by later plotted development. The adjacency of the government school with a large football field is integral to the significance of the site due to the annual sports events around the Independence Day. The site is used as a pedestrian thoroughfare due to the settlement that has taken place over the last decade. Large-scale urban projects may be limited due to the MoEF notification of 2010 according to which the census town became a part if the eco sensitive zone in the five-kilometer radius of Sultanpur National Park.

The biggest challenge in terms of urban development is that the heritage sites are not marked in any of the development plans. The development plans focus on expansion of the towns of Sohna and Farrukhnagar and shifting the focus outside the original settlements. The heritage sites lie within the municipal boundaries, or in the case of Garhi Harsaru, within the village boundary, hence their context is governed by the local bodies that have no involvement with the management of any of the sites and are ill equipped to deal with heritage or appreciate the interconnectivity of developmental decisions on the heritage sites. It is only due to MoEF notifications that the natural conservation and eco sensitive zones have been demarcated, but the implementation on ground may remain a challenge. In Garhi Harsaru, the plotted development that took place around the site over the last decade and a half has placed the Ashram at its center, but in the other cases, the center has shifted.

None of the local bodies of the towns have the capacity to deal with heritage and culture. These towns are stuck in a dilemma of decentralization versus centralization. While MoEF and TCPD may have a larger vision, they do not address concerns of heritage and the local governance machinery lacks sensitivity. Hence, the custodians of the sites deal with the issues within the property lines of the sites and try to wield influence regarding decision making in the immediate surroundings as and when it becomes possible. The holistic or integrated development approach is completely missing in these small and medium towns. While the location of the Shahi Masjid and Shiv Kund are linked with the geographical setting of the Aravallis and the water catchment area, in case of Garhi Harsaru, it is only incidental that the MoEF notification became applicable. 


\section{IMPACT OF SOCIAL AND POLITICAL EVENTS}

The physical interventions in the four cases have been triggered by national, regional and local events within the last century, directly or indirectly. The national events include Independence and Partition of India, the 1984 riots, demolition of Babri Masjid in 1992 and the court ruling regarding the same. The retaining of Muslims in Mewat by Gandhi Ji, the environment becoming conducive for Muslims in the 1960s are regional phenomena. The winning of case in Lahore Court for Shiv Kund in 1940s and the in migration of population over the last two decades in Garhi Harsaru are more localized phenomena that have had a major impact on the interventions being made at the sites.

There is a strong potential of influence of political will in decision making with respect to such sites. Patronization of the Shiv Kund by Tau Devi Lal in the 1970s and 80s and the contributions made by political figures from the region towards construction activity at Garhi Harsaru and Shiv Kund are examples of the phenomena. In a case such as Shiv Kund, where the property is legally with the Kund Committee, the social constitution of the committee members has an impact on affiliation with socio-political agendas such as the one seen in 2017-18 where the Rajput community opposed the release of the film Padmaavat.

The formation of the Waqf Board at the national level and the following decentralization of it affect all sites directly, except the Shiv Kund that sees an indirect impact. The weak control of the Waqf Board over the sites has enabled the current custodians to appropriate the sites and keep these active with independent decision making about interventions and use.

\section{POTENTIAL LINKAGES WITH DEVELOPMENT}

The challenges of linkage of heritage with development that the cases demonstrate are particularly relevant to the small and medium towns and the developmental approach in the state of Haryana. State initiatives have been limited to interventions like setting up of tourist complexes such as the one at Sohna that remain completely disconnected from the towns. Interventions have been extrinsic to the towns and focused on presence of railway lines and highways, creation of industrial hubs, commercial corridors and fulfilling projected housing demands. None of these towns has the potential to attract the attention of central government schemes such as PRASAD or HRIDAY and these are stuck in a limbo, primarily governed by commercial forces that are changing the context at an alarming pace.

The historic urban landscape approach or cultural landscape approach are theoretically applicable to the context of each of the towns, but are far from becoming an implementable reality. Even the first step of integrating existing mapping of heritage sites by agencies such as INTACH and AIIS in the records of the local bodies and development plans is missing. This integration can be the starting point of developing linkages with development. Mapping interdependencies of the sites with their ecological

context and maintaining continuity of these would be the next step. The motivation can come from the custodians and other local stakeholders, both in terms of envisioning themselves as beneficiaries and empowered contributors. A bridging of the disconnect in the heritage discourse at the level of local stakeholders, local government and state government agencies is the need of the hour, if an heritage linked model of development is to be established for unprotected built heritage sites in the region under study.

\section{RESULT AND DISCUSSION}

The sites find direct linkages with the physical, socio-political and developmental context. While the cases themselves are maintained and managed without government interventions, there are many intersections with governmental and non-governmental organization frameworks at the micro and macro level.

Physical setting plays a significant role, establishing linkages with the immediate context such as the Aravallis at Shiv Kund, the government school with a football field at Garhi Harsaru, the parking and space around at the Shahi Masjid and shifting of commercial activities at Farrukhnagar. Linkages also exist at the regional level, with villages around serving as the catchment in terms of patronage, connections with regional fairs and ecology. These linkages need to be mapped spatially and become a significant parameter that is considered during developmental planning at the local and regional level. Networks of livelihoods and community associations are significant as interdependencies that keep the built heritage alive, forming a significant component of the context.

The fact that socio-political events have a direct impact on the sites, acting as disruptions to the process of continuity is another significant consideration. These social and political events that can affect heritage, feed into a larger understanding of the ripple effect of national or regional events on built heritage and its values.

Development planning in the small and medium towns does not consider heritage, or any cultural linkages at the local or regional level ${ }^{25}$. Local governance lacks capacity to deal with concerns around heritage in these towns and state interventions have been ignorant of the same. The poor capacity and lack of engagement of formal local governments and weakcontrol of the Waqf Board have created a vacuum that has been filled by local processes and stakeholders. While the intervention of governmental and non-governmental bodies is not an imperative in the maintenance and management of the sites, they can play a significant role in the development of a holistic and integrated developmental approach, based on mapping of heritage and its cultural linkages at local and regional level.

\footnotetext{
${ }^{25}$ This is pertinent to the three small and medium towns of Gurgaon District in which the four case studies are situated. Master plans of cities such as Delhi in which the four case studies are
have a stronger focus on heritage. 
The linkage of built heritage needs to be mapped in a spatial as well as socio-political context, to guide development and an understanding of our history, culture, politics and society. The mapping of the networks, particularly in small and medium towns can help in retaining linkages with villages that depend on them and acknowledging regional cultural phenomena. This in turn can help in developing a mechanism of heritage impact assessment before any development is proposed. Strengthening the capacity of local stakeholders, local governance and District administration can be useful steps towards this objective.

These findings set a forward path for inclusive planning that connects heritage and development. It is important to address the dynamics at play in the form of socio-political claim making processes and linkages with physical setting and larger region to incorporate influencing parameters holistically.

Each of the four cases are significant landmarks that reflect contemporary processes of value generation and have the potential to contribute to the development of the areas in which they are situated. If we envision a model for inclusive and participatory development in small and medium towns with built heritage and layers of associations, the formal as well as informal processes of use and management need to be understood, to avoid excluding the local stakeholders and segments of the community that have been marginalized in the course. Particularly in the small and medium towns, the average to laggard status of basic infrastructure emphasizes on the need for support from state and central government. In case such support comes in the form of policy, guidelines, legislation or funding, it is imperative that the formal and informal local processes are not disrupted and the formal and informal stakeholders are included in the documentation, research, capacity building, communication and decision making in a consultative manner.

Hence, sustainable development that is linked with heritage requires an interdisciplinary mapping of heritage resources, along with the aspects in the wider context that generate processes due to which the heritage resources gain contemporary values.

\section{REFERENCES}

1. UNDP, "Goal 11: Sustainable Cities and Communities", Sustainable Development Goals, 2019. Available: https://www.undp.org/content/undp/en/home/sustainable-development-g oals/goal-11-sustainable-cities-and-communities.html (accessed Sept. 15, 2019).

2. Directorate of Census Operations, District Census Handbook: Gurgaon, Chandigarh, Haryana: Directorate of Census Operations, 2011.

3. P.G. Munjal, "Participatory Approach for Cultural Heritage Resource Management in Small Towns", in Public Participation in Planning in India, A. Kumar, A \& P. Prakash, Eds. Newcastle upon Tyne: Cambridge Scholars Publishing, 2016, pp. 155-184.

4. Delhi Development Authority, Master Plan for Delhi-2021. New Delhi DDA, $2017 . \quad$ Available: https://dda.org.in/tendernotices_docs/may1/MPD-2021_31.03.2017260 417.pdf (accessed Oct. 14, 2019).

5. Department of Town and Country Planning Government of Haryana, Development Plans and Notifications. Haryana: TCP Haryana, 2019. Available: https://tcpharyana.gov.in/DevelopmentPlan.htm (accessed Oct. 14, 2019)
6. F. Bandarin, J. Hosagrahar and F. S. Albernaz, "Why Development Needs Culture," Journal of Cultural Heritage Management and Sustainable Development, vol. 1, no. 1, pp. 15-25.

7. United Nations, New Urban Agenda. United Nations, 2017. Available: http://habitat3.org/the-new-urban-agenda/ (accessed Oct. 15, 2019).

8. HSMI-HUDCO Chair-NIUA Towns of India: Status of Demography, Economy, Social Structures, Housing and Basic Infrastructure. 2016.

9. UNESCO Recommendation on the Historic Urban Landscape, including a glossary of definitions. 2011. Available: http://portal.unesco.org/en/ev.php-URL_ID=48857\&URL_DO=DO_T OPIC\&URL_SECTION=201.html (accessed Oct. 15, 2019).

10. L. Smith, Uses of Heritage, London and New York: Routledge, 2006.

11. World Heritage Center. The World Heritage Convention. UNESCO. Available: https://whc.unesco.org/en/convention/ (accessed Oct. 15, 2019).

12. S. S. Imon, "Public Participation and Sustainable Urban Conservation," Context: Built, Living and Natural, vol. 12, 2016, pp. 21-30.

13. A. Galla, "Culture and Development in New Urban Agenda: Learning from Hoi An and Amravati," Context: Built, Living and Natural, vol. 12, 2016, pp. 11-20.

14. F. Matero, "Ethics and Policy in Conservation," Conservation, A Getty Conservation Institute Newsletter, vol. 15, no. 1, 2000, pp. 5-9.

15. TCPD, Final Development Plan of Gurgaon-Manesar Urban Complex 2031 A.D. Chandigarh: Government of Haryana, 2012.

16. TCPD. Final Development Plan of Sohna 2031 A.D. Chandigarh: Government of Haryana, 2012.

17. A. Cunningham, Report of a tour in Eastern Rajputana in 1882-83, vol. XX. New Delhi: ASI, 2000.

18. Punjab Government, Punjab District Gazetteer, Vol. IV A: Gurgaon District. Lahore: Punjab Government, 1910.

19. TCPD. Draft Development Plan of Farrukhnagar 2031 A.D. Chandigarh: Government of Haryana, 2012.

20. MoEF. The Gazette of India: Extraordinary, Part II section 3 Sub-section (ii). New Delhi: Government of India, Jan. 27, 2010.

\section{AUTHORS PROFILE}

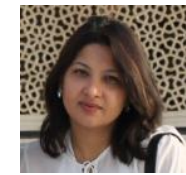

Parul G Munjal is an Associate Professor at Sushant School of Art and Architecture and heads the two year 'Masters of Architecture in Built Heritage' program at the School. She is a Conservation Architect and has worked on a number of World Heritage Dossiers along with plans for conservation, management and interpretation of heritage sites in India. Munjal is Editor of 'Context: Built, Living and Natural', an internationally refereed Journal. With a strong orientation towards interdisciplinary research, Munjal has published widely in journals of repute, in the areas of heritage conservation, community based approach and heritage tourism. The focus of her doctoral research was on built heritage of small and medium towns in Gurgaon District. 